\title{
Treatment of stiff thoracic scoliosis by thoracoscopic anterior release combined with posterior instrumentation and fusion
} Kenneth MC Cheung*1, Jing-ping Wu르, Qing-he Cheng ${ }^{3}$, Bonnie SC Ma1, Jichang $\mathrm{GaO}^{3}$ and Keith DK Luk ${ }^{1}$

\author{
Address: ${ }^{1}$ Department of Orthopedics and Traumatology, Queen Mary Hospital, The University of Hong Kong, 102 Pokfulam Road, Hong Kong, \\ China, ${ }^{2}$ Department of Orthopaedics, Jinshan Hospital, Fudan University, Shanghai, China and ${ }^{3}$ The 211 th Hospital of PLA, Harbin, China \\ Email: Kenneth MC Cheung* - cheungmc@hku.hk; Jing-ping Wu - wu_j_p@hotmail.com; Qing-he Cheng - cqh211@yahoo.com.cn; \\ Bonnie SC Ma - bonnie.msc@gmail.com; Ji-chang Gao - bingyu651226@sina.com; Keith DK Luk - hrmoldk@hku.hk \\ * Corresponding author
}

Published: 15 October 2007

Journal of Orthopaedic Surgery and Research 2007, 2:16 doi:10.1186/1749-799X-2-16

This article is available from: http://www.josr-online.com/content/2/1/16

(C) 2007 Cheung et al; licensee BioMed Central Ltd.

This is an Open Access article distributed under the terms of the Creative Commons Attribution License (http://creativecommons.org/licenses/by/2.0), which permits unrestricted use, distribution, and reproduction in any medium, provided the original work is properly cited.
Received: 23 January 2007

Accepted: 15 October 2007

\begin{abstract}
Background: Thoracoscopic anterior release has been shown that it can effectively improve spinal flexibility in animal and human cadaveric studies, and has been advocated for use in patients with scoliosis. This prospective case series aims to investigate the improvement of the spinal flexibility and the effectiveness in deformity correction by anterior thoracoscopic release and posterior spinal fusion.
\end{abstract}

Methods: Eleven patients with stiff idiopathic thoracic scoliosis underwent anterior thoracoscopic release followed by posterior instrumentation. The average number of discs excised was five. Spinal flexibility was assessed by the fulcrum bending technique. Cobb angle before and after the anterior release was compared.

Results: The patients were followed for an average of 5.6 years (range 2.2 to 8.1 years). Fulcrum bending flexibility was increased from $39 \%$ before the thoracoscopic anterior spinal release to $54 \%$ after the release. The average Cobb angle before anterior release was $74^{\circ}$ on the standing radiograph and $45^{\circ}$ with the fulcrum-bending radiograph. This reduced to $34^{\circ}$ on the fulcrumbending radiograph after the release, and highly corresponded to the $31^{\circ}$ measured at the postoperative standing radiograph.

Conclusion: It was demonstrated in patients with stiff idiopathic thoracic scoliosis that thoracoscopic anterior spinal release can effectively improve the spinal flexibility and increase the correction of the spinal deformity.

\section{Background}

Anterior spinal release can improve spinal flexibility and maximize correction of spinal deformity effectively when treating stiff thoracic scoliosis. It is inevitable to incise the chest wall muscles to remove intervertebral disc in the open chest procedures, which leads to multiple surgical complications such as reduced airway flow, post-operative lung collapse, blood loss, chest wall scarring and prolonged hospitalization. Nevertheless, utilizing videoassisted thoracoscopy in anterior spinal release can effectively reduce or prevent these surgical complications $[1,2]$. 


\section{Methodology}

Between June 1997 and June 2003, 11 patients with stiff thoracic scoliosis underwent thoracoscopic anterior release, followed by either staged (one week apart) or synchronous posterior instrumentation and spinal fusion. Routine standing anterior-posterior radiograph was taken for each patient to determine the Cobb angle (Figure 1). Definition of stiff scoliosis is that the Cobb angle being larger than 40 degrees in a fulcrum bending X-ray. The fulcrum bending radiograph was taken with a cylindrical fulcrum placed over the apex of the scoliotic curve (Figure 2, 3) [3]. The patient was asked to lie sideways over a fulcrum made from a large plastic cylinder with extra padding for comfort, using the body weight of the head and lower limbs to straighten the spine over the apex of the convex curve. The mean age at the time of operation was 16.5 years (range 11.9 - 35.5 years). According to King's classification, the curve types were as follows: type I (1), type II (5), type III (5).

The surgical technique of thoracoscopic-assisted anterior release was as described in the previous publication of Luk et al. [2]. In brief, the thoracoscopic anterior release was done under general anesthesia, a keyhole of $2 \mathrm{~cm}$ diame-

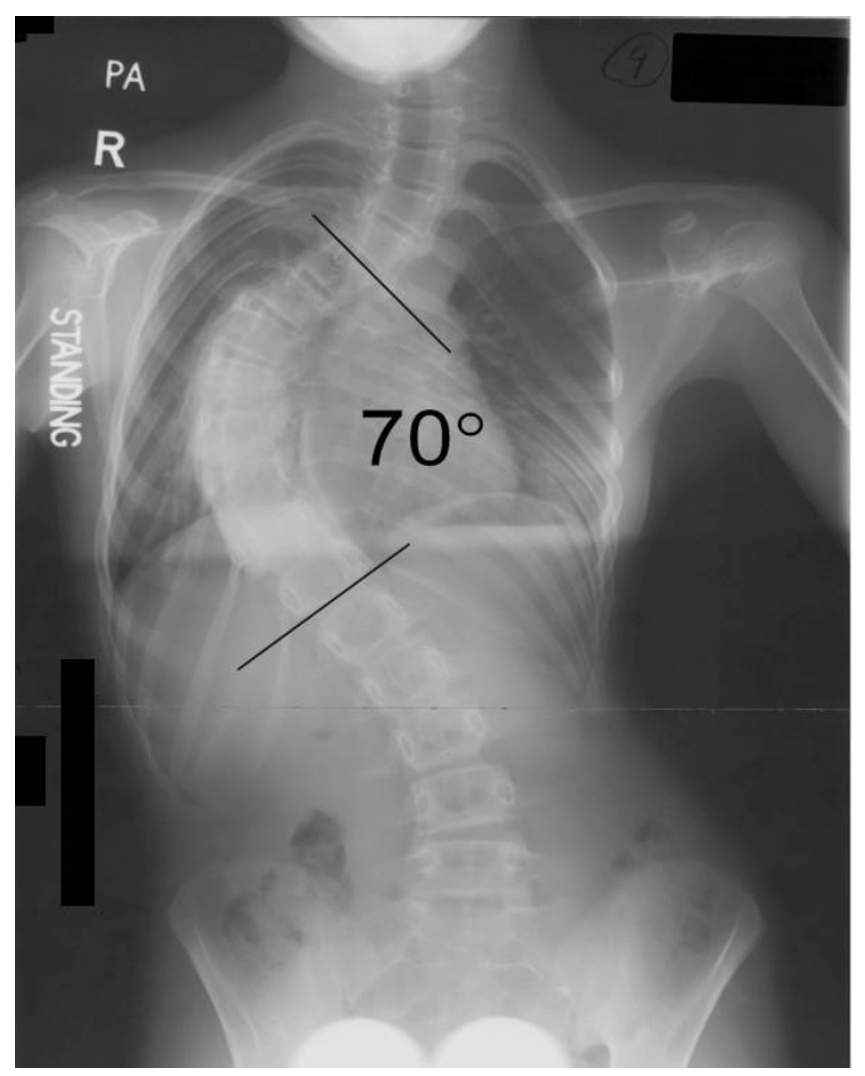

Figure I

Standing radiograph before anterior release.

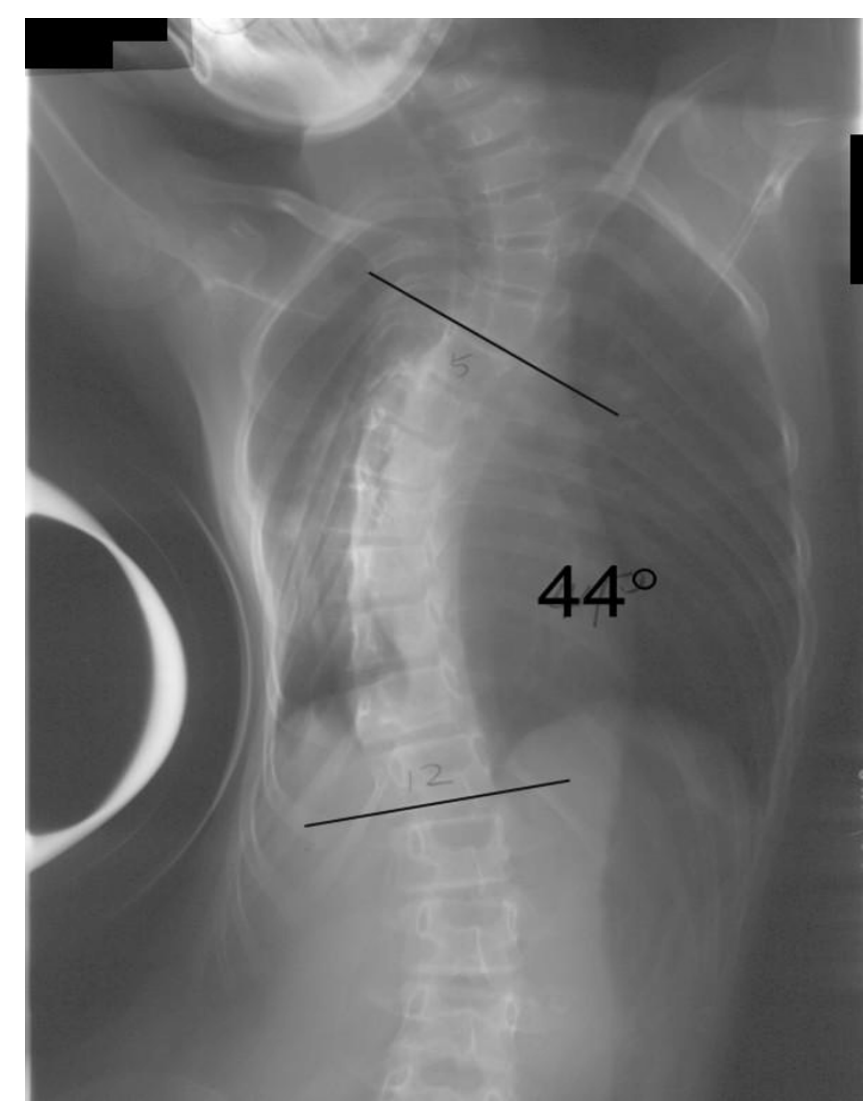

Figure 2

Fulcrum bending radiograph before anterior release.

ter was opened over the mid-axillary line at the sixth or seventh intercostal space at the convex side of the scoliotic curve. 3 to 4 more manipulative keyholes were opened near the mid-axillary line depending levels needed to be exposed. Ribs were not removed. Intervertebral discs near the apex were excised, including nucleus pulposus and cartilaginous end-plates. The posterior longitudinal ligament could be reached when excising the cephalic intervertebral disc. In general, 3-6 intervertebral discs had been excised and the average number of discs excised was five. Posterior surgery adopted pedicle hook system, and pedicle screws in the form of hybrid constructs were also used in the later part of the study (Figure $4 \& 5$, Table 1). For King type I (double curve, lumbar major), both thoracic and lumbar curves were corrected and fused, while for King type II and type III single thoracic curves, they were selectively fused to the lower thoracic or upper lumbar spine.

Two methods were utilized to test for the effectiveness of thoracoscopic anterior release in increasing spinal flexibility. First one was the direct comparison between the preand post-operative angles in fulcrum bending radiographs. Second one was comparing the pre-operative ful- 


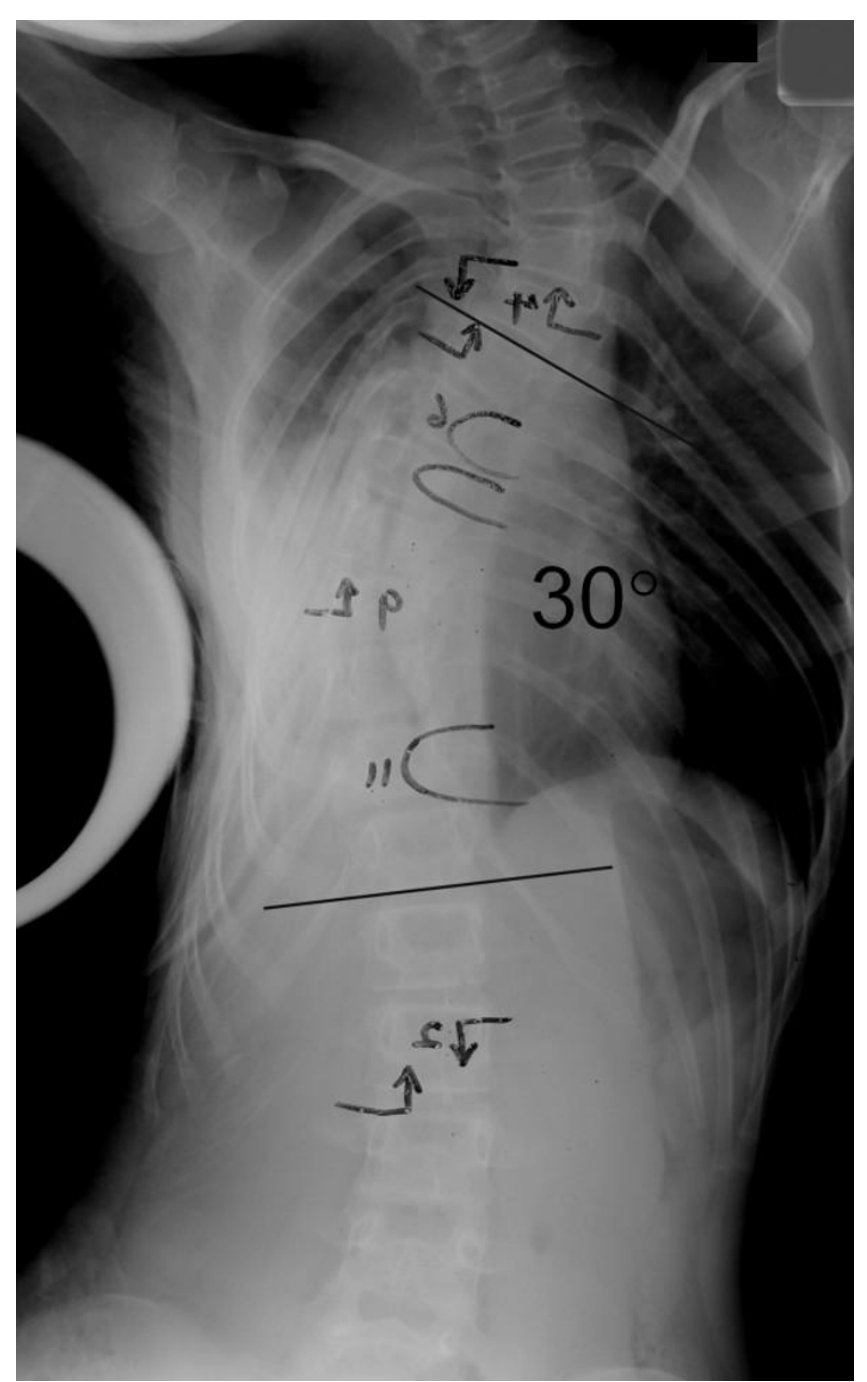

Figure 3

Fulcrum bending radiograph after anterior release.

crum bending radiograph with the post-operative correction, using the fulcrum bending radiograph to assess the spinal fulcrum bending flexibility. The fulcrum bending flexibility was calculated as: Fulcrum Bending Flexibility $(\%)=($ Pre-operative Cobb Angle - Fulcrum Bending Cobb Angle)/Pre-operative Cobb Angle $\times 100 \%$. This fulcrum bending flexibility can be used to assess the change in spinal flexibility after anterior release. Statistical analyses were performed using paired t-test, with $\mathrm{p}<0.05$ being statistically significant.

\section{Results}

All thoracoscopic anterior release surgeries were successfully done, none of the case was obliged to become open surgery. Average time for anterior release was 4.3 hours (range from 3 - 6 hours), and average blood loss was 180 $\mathrm{ml}$ (range from $40-400 \mathrm{ml}$ ). No obvious intra- or post-

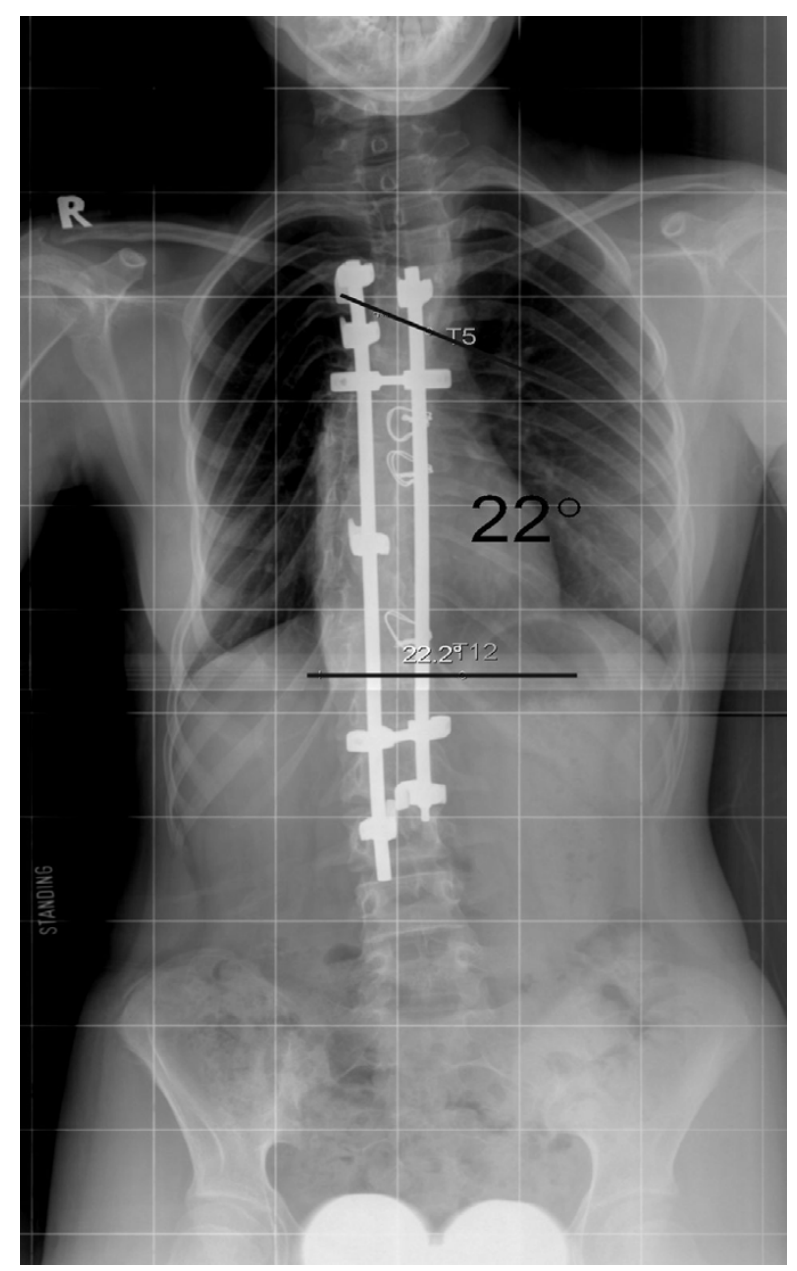

\section{Figure 4}

Standing radiograph after posterior instrumentation.

operative complications. Mean follow-up length was 5.6 years $(2.2-8.1$ years $)$. Pre-operative mean fulcrum bending flexibility was 39\%, with a statistical significant increment $(\mathrm{p}<0.05)$ of $15 \%$ after anterior release, the mean fulcrum bending flexibility reached $54 \%$ post-operatively. The mean Cobb angle in standing radiograph was 74 degree before anterior release, and that in fulcrum bending radiograph was 45 degree. After anterior release, however, the mean Cobb angle in fulcrum bending radiograph was 34 degree. The actual mean Cobb angle in standing radiograph after posterior instrumentation with bone grafting was 31 degree (see table 2).

\section{Discussion}

Open chest surgery was adopted to improve the spinal flexibility in stiff thoracic scoliosis. With the aid of videoassisted thoracoscopic surgery (VATS), the traditional open chest anterior release surgery could be replaced with 


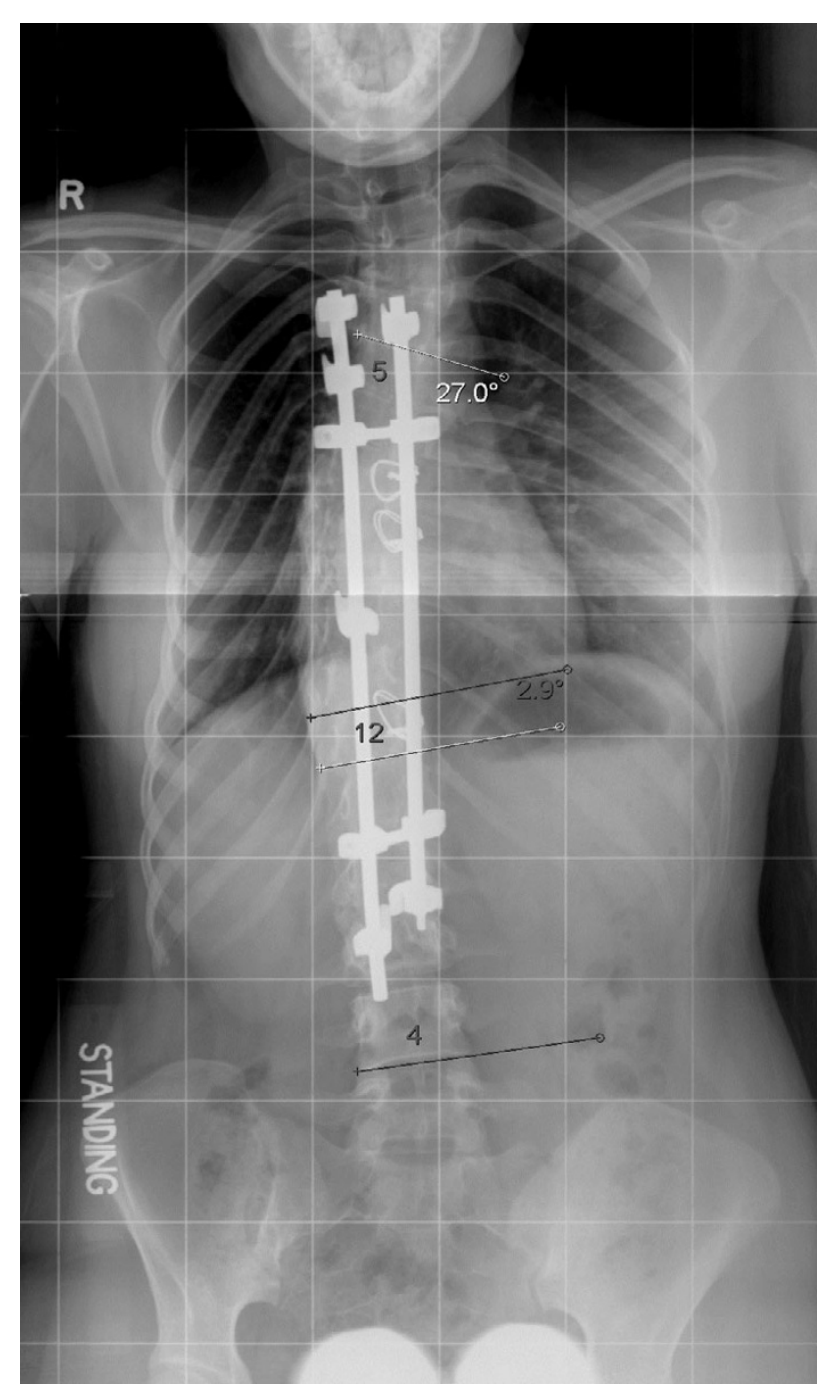

Figure 5

Standing radiograph 5 years after surgery.

micro-trauma and less complications [4-6]. While some physicians thought thoracoscopic release and open chest release have different abilities to release the spine, and that only open chest surgery excising ribs and complete excision of intervertebral discs could successfully and

Table I: Number of patients with different instrumentations

\begin{tabular}{ccc}
\hline $\begin{array}{c}\text { Instrumentation } \\
\text { System }\end{array}$ & $\begin{array}{c}\text { Number } \\
\text { of patients }\end{array}$ & Hooks only or hybrids \\
\hline $\begin{array}{c}\text { Isola } \\
\text { CD Horizon }\end{array}$ & 3 & $\begin{array}{c}\text { Hybrids } \\
\text { TSRH }\end{array}$ \\
Moss Miami & 4 & Hook (I), Hybrids (3) \\
Hook \\
\hline
\end{tabular}

completely release a stiff spine. VATS has been shown that it can effectively improve spinal flexibility in animal and human cadaveric studies [7]. Its use in human patients with scoliosis have been supported by a number of studies [8-10], however, all except one case report demonstrated that it was effective at improving spinal flexibility.

In our study, stiff scoliosis curve was defined as the residual Cobb angle equal to or larger than 40 degrees in a fulcrum bending radiograph. This concept of fulcrum bending flexibility was first suggested and applied clinically by the authors. It was used to select the fusion segments and predict the correction after surgery, so that patients and their family could be informed the treatment effect pre-operatively [11-14]. Previous researches showed that this can reflect the spinal flexibility, comparison between pre-operative fulcrum bending radiographs and post-operative correction demonstrated 98\% accuracy, and the fulcrum bending flexibility can predict the postoperative correction of rib hump accurately [13]. The fulcrum bending flexibility applied in this study served as an excellent method to judge the treatment effect of thoracoscopic anterior release. This cohort included 11 patients with stiff thoracic scoliosis, with pre-operative fulcrum bending Cobb angle larger than 40 degrees, and a mean of 45 degrees. The mean post-thoracoscopic fulcrum bending Cobb angle was 34 degrees, while the mean Cobb angle in standing radiograph after posterior instrumentation was 31 degrees. These two were so close, and it demonstrated that the pre-operative fulcrum bending flexibility could accurately predict the result of surgical correction. The side-bending radiographs taken in supine lying could roughly predict the post-operatively correction, thus the fulcrum bending radiograph is superior to the traditional side-bending radiograph to predict the pos-operative Cobb angle.

Fulcrum bending flexibility is expressed as the difference between the Cobb angles measured on the fulcrum bending and preoperative radiographs divided by the preoperative Cobb angle [13]. In this series, the mean fulcrum bending flexibility also improved from $39 \%$ pre-operatively to $54 \%$ post-operatively, with $15 \%$ increment. This is a strong evidence for thoracoscopic anterior release could improve spinal flexibility among patients with stiff thoracic scoliosis, so that the curves could be corrected.

When describing surgical correction, the authors would propose that the spinal flexibility need to be taken into account, and that this is best decribed by the fulcrum bending correction index (FBCI). The FBCI is expressed as correction rate divided by fulcrum flexibility; an FBCI of $100 \%$ indicates that the surgical correction has taken up all the flexibility as revealed by the fulcrum bending radiograph [13]. In this cohort, all patients had a FBCI of 
Table 2: Cobb angle measurements of all cases $\left({ }^{\circ}\right)$

\begin{tabular}{|c|c|c|c|c|c|c|c|c|c|c|c|c|}
\hline & Case I & Case 2 & Case 3 & Case 4 & Case 5 & Case 6 & Case 7 & Case 8 & Case 9 & Case 10 & Case II & Mean \\
\hline Pre-operative Standing View & 65 & 76 & 75 & 78 & 61 & 82 & 80 & 70 & 70 & 76 & 75 & 74 \\
\hline Pre-operative Fulcrum Bending View & 43 & 41 & 45 & 45 & 40 & 46 & 45 & 53 & 44 & 45 & 51 & 45 \\
\hline Post-operative Fulcrum Bending View & 35 & 28 & 40 & 30 & N/A & 34 & 32 & 36 & 30 & 34 & 40 & $34^{\Delta}$ \\
\hline Post-operative Standing View & 32 & 28 & 30 & 28 & 26 & 29 & 28 & 33 & 22 & 32 & 35 & $3 I^{*}$ \\
\hline Correction Rate (\%) & 50.7 & 63.2 & 60 & 64.1 & 57.4 & 64.6 & 65 & 52.9 & 68.6 & 57.9 & 57.1 & 58.1 \\
\hline Fulcrum Flexibility (\%) & 46.2 & 63.2 & 46.7 & 61.5 & N/A & 58.5 & 60 & 48.6 & 57.1 & 55.3 & 50 & 57.1 \\
\hline $\mathrm{FBCl}(\%)$ & 109 & 100 & 128 & 104 & N/A & 110 & 108 & 109 & 120 & 105 & 114 & 102 \\
\hline
\end{tabular}

Note I: Compare with pre-operative fulcrum bending view $\Delta p<0.05, * p<0.05$

Note 2: Unable to take post-operative fulcrum bending radiograph for case 5 due to post-operative wound pain

larger than $100 \%$, meaning anterior thoracoscopic release with posterior spinal fusion could over-correct the stiff scoliosis curves. In fact, previous study by the authors demonstrated that ability to correct scoliosis deformity using four different instrumentations was the same [15].

Due to inexperience at the beginning, only 3-4 intervertebral discs were excised during thoracoscopic anterior release, and the posterior surgery was performed 1 week later. It did, however, provide the conditions to prove the effectiveness of anterior release, and verify the in vivo spinal flexibility improvement with anterior release. With increasing experience, 5-6 intervertebral discs were excised in recent cases, and posterior instrumentation with bone grafting could be done at the same stage. Anterior release excised 5 intervertebral discs on average, with mean improvement of 16 degrees, illustrated that excision of a intervertebral disc could correct approximately 3 degrees. Although after excision of intervertebral discs, no anterior bone grafting was performed, the follow-up radiographs after 3 years revealed good fusion status, which showed that solely posterior bone grafting could achieve satisfactory fusion.

\section{Competing interests}

The author(s) declare that they have no competing interests.

\section{Authors' contributions}

KMCC participated in the design of the study and carried out the thoracoscopic surgery. JPW assessed the radiographic Cobb's angles and assisted in the surgery. QHC performed the statistical analysis and helped to draft the Chinese manuscript. BSCM drafted the manuscript. JCG collected the data. KDKL conceived of the study, and participated in the design of the study and coordination. All authors read and approved the final manuscript.

\section{Acknowledgements}

Written consent for publication was obtained from the patient or their relative.

\section{References}

I. Anand N, Regan JJ: Video-assisted thoracoscopic surgery for thoracic discdisease: Classification and outcome study of 100 consecutive cases with a 2-year minimum follow-up period. Spine 2002, 27:87I-879.

2. Luk KDK, Cheung KMC, Chiu SW: Thoracoscopic-assisted anterior release of the spine. J Orthop Surgery 1996, 4:5-I2.

3. Cheung KM, Luk KD: Prediction of correction of scoliosis with use of the fulcrum bending radiograph. J Bone Joint Surg Am 1997, 79: II 144-II 50.

4. Kim DH, Jaikumar S, Kam AC: Minimally invasive spine instrumentation. Neurosurgery 2002, 5 I(5 Suppl):SI5-S25.

5. Newton PO, Wenger DR, Mubarak SJ, Meyer RS: Anterior release and fusion in pediatric spinal deformity. A comparison of early outcome and cost of thoracoscopic and open thoracotomy approaches. Spine 1997, 22: I 398- 1406.

6. Niemeyer T, Freeman BJ, Grevitt MP, Webb JK: Anterior thoracoscopic surgery followed by posterior instrumentation and fusion in spinal deformity. Eur Spine J 2000, 9:499-504.

7. Newton PO, Cardelia JM, Farnsworth CL, Baker KJ, Bronson DG: A biomechanical comparison of open and thoracoscopic anterior spinal release in a goat model. Spine 1998, 23:530-535.

8. Faro FD, Marks MC, Newton PO, Blanke K, Lenke LG: Perioperative changes in pulmonary function after anterior scoliosis instrumentation: thoracoscopic versus open approaches. Spine 2005, 30: 1058-1063.

9. Newton PO, Marks M, Faro F, Betz R, Clements D, Haher T, Lenke L, Lowe T, Merola A, Wenger D: Use of video-assisted thoracoscopic surgery to reduce perioperatiev morbidity in scoliosis surgery. Spine 2003, 28:s249-s254.

10. Qiu Y, Wu L, Wang B, Yu Y, Zhu ZZ, Qian BP: Thoracoscopic and mini-open thoracotomic anterior correction for idiopathic thoracic scoliosis: a comparison of their clinical results. Chin J Surg 2004, 42: I 284-I 288.

II. Klepps SJ, Lenke LG, Bridwell KH, Bassett GS, Whorton J: Prospective comparison of flexibility radiographs in adolescent idiopathic scoliosis. Spine 200I, 26:E74-79.

12. Luk KD: RE: Prospective comparison of flexibility radiographs in adolescent idiopathic scoliosis. Spine 26: E74-9. Spine 200I, 26:2404.

13. Luk KD, Cheung KM, Lu DS, Leong JC: Assessment of scoliosis correction inrelation to flexibility using the fulcrum bending correction index. Spine 1998, 23:2303-2307.

14. Polly DW Jr, Sturm PF: Traction versus supine side bending. Which techniquebest determines curve flexibility? Spine 1998, 23:804-808.

15. Luk KDK, Cheung KMC, Wong YW: A prospective comparison of the coronal deformity correction in thoracic scoliosis using four different instrumentations and the fulcrum-bending radiograph. Spine 2004, 29:560-563. 